\title{
FREQUENCY AND CORRELATES OF POOR SLEEP QUALITY AMONG PATIENTS OF PARKINSON'S DISEASE
}

\author{
Syed Sakhawat Kazmi, Zahid Hassan, Waseem Alamgir, Asif Hashmat, Ali Yosuf, Atifa Gillani
}

Pak Emirates Military Hospital/National University of Medical Sciences (NUMS) Rawalpindi Pakistan

\begin{abstract}
Objective: To determine the frequency of poor sleep quality among the patients of Parkinson's disease (PD) and analyze its relationship with the socio-demographic factors.

Study Design: Correlational study.

Place and Duration of Study: Pak Emirates Military Hospital Rawalpindi, from Jan 2019 to Jun 2019.

Methodology: One hundred and fifty patients of Parkinson's disease were approached to participate in this study. Pittsburgh sleep quality index (PSQI) was the psychometric tool used to assess the study parameter for the patients. Age, gender, duration of illness, poly pharmacy and tobacco smoking were corelated with presence of poor quality of sleep among the patients of Parkinson's disease.

Results: Out of 150 patients of Parkinson's disease screened through Pittsburgh sleep quality index, 85 (56.7\%) showed the presence of poor sleep quality while $65(43.3 \%)$ had good sleep quality. Mean age of the patients was $66.2 \pm 4.648$ years. After applying the logistic regression, we found that increasing age and longer duration of illness had significant association with the presence of poor sleep quality among the patients of Parkinson disease.

Conclusion: Previously considered a pure motor disorder, Parkinsonism has a lot of other neuro-psychiatric manifestations as well. Poor sleep quality turned out to be one of these non-motor problems associated with this chronic debilitating illness. Increasing age and longer duration of illness among these patients emerged as independent risk factors for poor sleep quality in Parkinsonism.
\end{abstract}

Keywords: Parkinson's disease, Sleep quality, Socio-demographic factors.

This is an Open Access article distributed under the terms of the Creative Commons Attribution License (http://creativecommons.org/licenses/by/4.0), which permits unrestricted use, distribution, and reproduction in any medium, provided the original work is properly cited.

\section{INTRODUCTION}

Parkinson's disease (PD) was previously believed as a neurological disorder with prominent motor involvement. For years the focus of treatment was on improvement of the tremors, bradykinesia and rigidity ${ }^{1}$. As the number of patients seeking treatment and coming regularly to the neurology clinics increased, clinicians started observing other manifestations of this degenerative disease as well. Now it has emerged as a multisystem disorder with a full range of non-motor symptoms in addition to the routine motor symptoms which were considered hallmark of PD ${ }^{2,3}$. Studies involving the local population have also demonstrated a high frequency of these nonmotor symptoms among the patients of $\mathrm{PD}^{4,5}$.

Most of the neurological disorders either present as or during the course of illness show

Correspondence: Dr Syed Sakhawat Kazmi, Department of Neurology, PEMH Rawalpindi Pakistan

Received: 14 Feb 2020; revised received: 14 Jul 2020; accepted: 16 Jul 2020 the presence of neuropsychiatric symptoms. Depression, anxiety, fatigue and sleep problems are the features commonly reported with many neurological disorders 6,7 . Non motor symptoms of Parkinsonism also involve many of these neuropsychiatric symptoms. Depression, psychosis and dementia have been encountered among these patients in routine clinical practice ${ }^{5}$. Sleep problems including insomnia and poor sleep quality have also been the area of interest for clinicians as well as researchers as sleep is one of the most important biological functions of human body. Neuro-chemical basis of Parkinson may be responsible for the presence of neuropsychiatric symptoms including poor sleep quality ${ }^{8}$. Long standing nature may also prone the individual towards psychological problems which may lead to sleep issues ${ }^{9}$.

Various studies have highlighted sleep problems among the patients of PD. Shen et al concluded in their analysis that all types of sleep 
disorders have been more prevalent among the patients of PD as compared to healthy controls ${ }^{10}$.

Neurology and psychiatry are both developing specialty in our country with availability of trained professionals limited usually to tertiary care set ups of big cities only. Therefore chances of patients having a long untreated course of illness are an expected finding. Moreover we usually lack liaison facilities which deprive the patient from the holistic approach of treatment. Limited local work looked purely into the impact on the biological functions like sleep. We planned this study with the rationale to determine the frequency of poor sleep quality among the patients of PD and analyze its relationship with the sociodemographic factors.

\section{METHODOLOGY}

This correlational was conducted at the neurology department of a tertiary care hospital of Rawalpindi between January 2019 to June 2019. Sample size was calculated by using the sample size calculator by using population prevalence proportion of various kinds of sleep problems in PD as $90 \%{ }^{5}$. Non probability consecutive sampling technique was used to gather the sample. Screening was performed on all the patients of PD between the age of 50 and 80 years reported for follow up visit or referred from other centers, diagnosed ${ }^{11,12}$ at least 6 months ago by a consultant neurologist. Patients outside the designated age bracket, or those with previous significant psychiatric or substance use history or those delirious or had dementia at the time of interview were excluded from the study. Any neoplastic, non neoplastic lesion of brain or any evidence of stroke or brain damage was also made part of the exclusion criteria for this study. Patients who had past history of depression or any type of sleep problems prior to the onset of PD were also not included in the study. Patients using benzodiazepines or other hypnotics before or after the onset of Parkinsonism were also excluded from the final analysis.

IREB letter no PEMH/A/28 dated Dec 1, 2018 was taken from the ethics committee as approval for the study. Patients gave consent in writing after description of study. Diagnosis of PD should have been made at least six months ago by a consultant neurologist based on the routine criteria after excluding all the secondary causes of the symptoms related to PD'13-15. The Urdu version PSQI and questionnaire was administered to the patients and they were asked to answer the questions according to their condition in last one month. Socio demographic variables were also collected. Variables in the study included age, gender, duration of illness, poly pha-macy and tobacco smoking. Names of patients were not recorded to keep the confidentiality. An independent assessor then interpreted and processed the data to avoid the bias.

\section{Pittsburgh Sleep Quality Index (PSQI)}

Various subjective and laboratory methods have been designed to look into the phenomenon of sleep. We used Pittsburgh Sleep Quality Index (PSQI) which is most commonly used self-rated subjective instrument to assess the quality of sleep. The PSQI is an effective and valid instrument for measure of quality and patterns of sleep. Validated Urdu version of PSQI was applied ${ }^{16,17}$. A global sum of " 5 " or greater indicates poor sleep quality in our study participants.

PSQI scores and general characteristics of the patients included in study were processed via descriptive statistics. Categorical variables were made for the presence and absence of poor sleep quality with cut score of 5 on PSQI. Pearson chisquare test was applied at initial phase to see the association. In second phase binary regression analysis was performed to look for the extent of correlation between dependent and independent variables with $p$-values $\leq 0.05$ as significant. Statistics Package for Social Sciences (SPSS) version 23 was used to carry out all the above-mentioned statistical tests.

\section{RESULTS}

A total of 159 patients of PD were approached to participate in the study. Two were unable to fill the required questionnaire. Two had depressive illness prior to the diagnosis of Parkin- 
sonism. Three had recent stroke. One was using benzodiazepines without the prescription of any physician and one smoked cannabis regularly. A total of 150 participants who had completion of the PSQI were included in the final analysis. One hundred and twelve were male while 38 were females. Mean age of the patients was $66.2 \pm 4.648$ years. Out of 150, $85(56.7 \%)$ showed the presence

\section{DISCUSSION}

Neurological illnesses usually have multi-dimensional symptomatology which demands holistic approach of the treating physician in order to cater for the wide range of symptoms. PD is no exception to this rule and has a big spectrum of signs and symptoms with which a patient can present in addition to the routine diagnostic

Table I: Characteristics of the study group and their PSQI scores.

\begin{tabular}{|c|c|c|c|}
\hline $\begin{array}{l}\text { Socio-demographic factors } \\
\text { Total, } n=150\end{array}$ & $\begin{array}{c}\text { Good sleep quality } \\
\text { (PSQI 0-5) } \\
\text { n (\%), } 65(43.3)\end{array}$ & $\begin{array}{c}\text { Poor sleep quality } \\
\text { (PSQI >5) } \\
\text { n (\%), } 85(56.7) \\
\end{array}$ & $p$-value \\
\hline \multicolumn{4}{|l|}{ Age } \\
\hline $\begin{array}{l}40-55 \text { year } \\
>60\end{array}$ & $\begin{array}{l}38(58.5) \\
27(41.5)\end{array}$ & $\begin{array}{l}22(25.8) \\
63(74.2)\end{array}$ & $<0.001$ \\
\hline \multicolumn{4}{|l|}{ Gender } \\
\hline $\begin{array}{l}\text { Male } \\
\text { Female }\end{array}$ & $\begin{array}{l}\text { Male } \\
\text { Female }\end{array}$ & $\begin{array}{l}\text { Male } \\
\text { Female }\end{array}$ & $\begin{array}{c}\text { Male } \\
\text { Female }\end{array}$ \\
\hline \multicolumn{4}{|l|}{ Duration of illness } \\
\hline $\begin{array}{l}<2 \text { years } \\
>2 \text { years }\end{array}$ & $\begin{array}{l}<2 \text { years } \\
>2 \text { years }\end{array}$ & $\begin{array}{l}<2 \text { years } \\
>2 \text { years }\end{array}$ & $\begin{array}{l}<2 \text { years } \\
>2 \text { years }\end{array}$ \\
\hline \multicolumn{4}{|l|}{ Smoking } \\
\hline $\begin{array}{l}\text { Non Smoker } \\
\text { Smoker }\end{array}$ & $\begin{array}{l}\text { Non Smoker } \\
\text { Smoker }\end{array}$ & $\begin{array}{l}\text { Non Smoker } \\
\text { Smoker }\end{array}$ & $\begin{array}{l}\text { Non Smoker } \\
\text { Smoker }\end{array}$ \\
\hline \multicolumn{4}{|l|}{ Poly-pharmacy } \\
\hline $\begin{array}{l}\text { No } \\
\text { Yes }\end{array}$ & $\begin{array}{l}\text { No } \\
\text { Yes }\end{array}$ & $\begin{array}{l}\text { No } \\
\text { Yes }\end{array}$ & $\begin{array}{l}\text { No } \\
\text { Yes }\end{array}$ \\
\hline
\end{tabular}

Table-II: The correlated factors relating to poor sleep quality among the patients of Parkinson disease: the binary logistic regression.

\begin{tabular}{l|c|c|c}
\hline & B & $p$-value & OR (95\% CI) \\
\hline Age (ref. is 60 years or less) & 1.378 & $<0.01$ & $3.967(1.879-8.376)$ \\
\hline Gender (ref. is male) & 0.050 & 0.907 & $1.051(0.455-2.428)$ \\
\hline Duration of illness (ref. is <2 years) & 1.211 & 0.001 & $3.356(1.616-6.969)$ \\
\hline $\begin{array}{l}\text { Poly-pharmacy (ref. is ischemic } \\
\text { stroke) }\end{array}$ & -0.451 & 0.230 & $0.637(0.305-1.330)$ \\
\hline Smoking (ref. is non-smoker) & 0.387 & 0.301 & $1.472(0.707-3.066)$ \\
\hline
\end{tabular}

of poor sleep quality, while 65 (43.3\%) had good sleep quality. Table-I shows the distribution of the patients with respect to the quality of sleep. Increasing age and longer duration of illness had significant association with poor sleep quality when chi-square was applied. Table-II shows that increasing age and longer duration of illness were strongly associated with the presence of poor sleep quality among the patients of PD when regression analysis was done. motor symptoms ${ }^{3,4}$. Liaison with other specialists usually has been the answer to non-motor symptoms of PD like chronic pain, constipation, urinary problems and psychiatric manifestations ${ }^{5}$. Patient usually complains himself regarding the urinary or bowel complains or other physical problems but usually unable to comprehend and communicate to the physician regarding the psychiatric problems. This study was designed with the aim to look for an important psychiatric 
rather biological parameter among the patients suffering from this degenerative disorder.

More than half of the target population reported poor sleep quality on the subjective questionnaire used in the study. It is in accordance with the results of previous studies done on this topic ${ }^{12,18}$. It is an eye opener for the clinicians in our set up as neurologists usually miss this inquiry from the Parkinsonism patients and psychiatrists are seldom involved in the management of these patients in our set up. These findings also highlight the importance of training the neurologists in this aspect of this progressive illness so that they could pick these problems early during the course of illness and improve the overall quality of life instead of just focusing on the motor part of illness.

A study conducted in our neighboring country Iran revealed a significant difference in the sleep quality scores of patients with PD as compared to the healthy controls ${ }^{11}$. Another interesting study regarding the treatment options available for motor and sleep problems of this multisystem disorder concluded that sleep problems also responded to the deep brain stimulation among the patients of parkinsonism ${ }^{12}$. Similar results were generated in our study where sleep quality was found poor among most of the study participants. Poor quality of life has been linked with bad sleepers in various studies done in the past $^{13}$. Cognition and routine day to day activities have also been affected. People who don't sleep well may have increase chances of developing other medical and psychiatric disorders ${ }^{14}$. In light of results of our study and these studies, sleep emerge as an important parameter which is to be screened among the patients with PD.

Advancing age of the patient had statistically significant association with presence of poor sleep quality on both of the statistical tests we used in the analysis. Past study done by Kharkar et al in 2018 have shown different results in this regard among the patients of $\mathrm{PD}^{12}$. Usually sleep quality worsen with the advancing age in individuals without any other significant comorbid so these results might be direct effect of aging only or PD in old age may represent long standing illness which has its own effects on all the biological functions including the sleep. Case control studies with healthy controls of same age may generate accurate results in this regard.

Long duration of illness also had a significant association with poor sleep quality in our target population. Reason might be direct damage to brain structures with the advancing illness as it is a progressive degenerative disease or psychological consequences of a long standing illness may lead to the sleep problems. Researchers in other parts of the world have also revealed the association of long duration of illness with sleep problems among these patients ${ }^{18}$. Therefore clinicians should pay adequate attention towards sleep cycle and other psychological problems inorder to identify and manage in time to maintain an adequate overall quality of life among these patients.

Most of the patients were males in our study. Male to female ratio was 2.9:1. Though there is a male predominance in the patients suffering from this illness ${ }^{5,10}$ but still such huge difference might be due to the sampling bias as sample has been drawn from a military hospital where most of the entitlement revolves around the male soldiers and officers. However no association with gender was found with the poor sleep quality which is in accordance with the existing study done by Kay et al in $2018^{18}$.

Clinical criteria and expertise of a consultant neuro-physician were used to diagnose the patients with PD but sleep quality was assessed by using the subjective psychometric tool which raises some methodological issues and become a limitation in generalizing the results of this study. Moreover liaison with the psychiatrist was not done in order to look for the psychiatric causes of sleep disturbances among the target population as they can be an important comorbid with the PD. As most of the target population was from the age bracket where other medical illnesses are also common. Though some were part of the ex- 
clusion criteria still their effect on quality of sleep should also have been taken into account. More studies in future addressing these limitations may generate generalizable results in this regard.

\section{CONCLUSION}

Previously considered a pure motor disorder, Parkinsonism has a lot of other neuro-psychiatric manifestations as well. Poor sleep quality turned out to be one of these non-motor problems associated with this chronic debilitating illness. Increasing age and longer duration of illness among these patients emerged as independent risk factors for poor sleep quality in Parkin-sonism.

\section{CONFLICT OF INTEREST}

This study has no conflict of interest to be declared by any author.

\section{REFERENCES}

1. Goubault E, Nguyen HP, Bogard S, Blanchet PJ, Bezard E, Vincent $C$, et al. Cardinal motor features of parkinson's disease coexist with peak-dose choreic-type drug-induced dyskinesia. J Parkinsons Dis 2018; 8(2): 323-31.

2. Chen $H$. The changing landscape of parkinson epidemiologic research. J Parkinsons Dis 2018; 8(1): 1-12.

3. Yu QJ, Yu SY, Zuo LJ, Lian TH, Hu Y, Wang RD, et al. Parkinson disease with constipation: Clinical features and relevant factors. Sci Rep 2018; 8(1): 567.

4. Saad S, Nomani AZ, Badshah M, Afzal A. Frequency of non-motor symptoms in parkinson disease: experience from Pakistan. Pak J Neurol Sci 2017; 12(1): 8-14.

5. Ahmad I, Zubair UB. Frequency of non motor symptoms among patients of Parkinson's disease in Pakistan. J Physiol Pharmacol 2016; 13(3): 16-19.
6. Lyketsos CG, Kozauer N, Rabins PV. Psychiatric manifestations of neurologic disease: where are we headed?. Dialogues Clin Neurosci 2007; 9(2): 111-24.

7. Han JW, Ahn YD, Kim WS, Shin CM, Jeong SJ, Song YS et al. Psychiatric manifestation in patients with parkinson's disease. J Korean Med Sci 2018; 33(47): e300.

8. Emamzadeh FN, Surguchov A. Parkinson's disease: biomarkers, treatment, and risk factors. Front Neurosci 2018; 12(3): 612.

9. Koyanagi A, Garin N, Olaya B, Ayuso-Mateos JL, Chatterji S, Leonardi $\mathrm{M}$, et al. Chronic conditions and sleep problems among adults aged 50 years or over in nine countries: a multicountry study. PLoS One 2014; 9(12): e114742.

10. Shen Y. Sleep disorders in parkinson's disease: present status and future prospects. Chin Med J Engl 2018; 131(8): 883-85.

11. Najafi MR, Chitsaz A, Askarian Z, Najafi MA. Quality of sleep in patients with Parkinson's disease. Int J Prev Med 2013; 4(Suppl2): S229-33

12. Kharkar S, Ellenbogen JR, Samuel M, Rizos A, Silverdale M, Chaudhuri KR et al. Changes in Parkinson's disease sleep symptoms and daytime somnolence after bilateral subthalamic deep brain stimulation in Parkinson's disease. Parkinsons Dis 2018; 4(3): 16-19.

13. Ishak WW, Bagot K, Thomas S, Magakian N, Bedwani D, Larson $\mathrm{D}$ et al. Quality of life in patients suffering from insomnia. Innov Clin Neurosci 2012; 9(10): 13-26.

14. Bhaskar S, Hemavathy D, Prasad S. Prevalence of chronic insomnia in adult patients and its correlation with medical comorbidities. J Family Med Prim Care 2016; 5(4): 780-84.

15. Marsili L, Rizzo G. Diagnostic criteria for parkinson's disease: from james parkinson to the concept of prodromal disease. Front Neurol 2018; 9(1): 156-59.

16. Hashmi AM, Khawaja IS, Butt Z, Umair M, Naqvi SH, Haq JU. The pittsburgh sleep quality index: Validation of the urdu translation. J Coll Physicians Surg Pak 2014; 24(2): 123-26.

17. Zubair UB, Butt B. Association of quality of sleep with cognitive decline among the patients of chronic kidney disease undergoing hemodialysis. J Ayub Med Coll Abbottabad 2017; 29(4): 619-22.

18. Kay DB, Tanner JJ, Bowers D. Sleep disturbances and depression severity in patients with Parkinson's disease. Brain Behav 2018; 8(6): e00967. 